\title{
Persistence and Horticultural Value of Inflorescence Dichotomy in Plantain
}

\author{
A. Tenkouano ${ }^{1}$ \\ Crop Improvement Division, International Institute of Tropical Agriculture, \\ PMB 5320, Oyo Road, Ibadan, Nigeria
}

Additional index words. Musa sp., phenotypic variation, multiple bunches, agronomic performance

Abstract. This study aimed to assess the persistence and horticultural value of bunch
dichotomy in plantain. Meristematic tissue was collected from a plant of the cultivar UNN
showing a double-bunch phenotype and cultured in vitro. Ninety-five seedlings were
acclimatized for 6 to 8 weeks in a greenhouse, prior to transfer to the field. Field evaluation
was carried out at three experimental farms (Abuja, Ibadan, and Onne) of the Interna-
tional Institute of Tropical Agriculture, in Nigeria. Micropropagated plants of two
plantain accessions, 'Agbagba' and 'Obino l'ewai', that produce single bunches were
included as controls. Reversal of the double-bunch phenotype to a single-bunch phenotype
was observed. Few plants underwent an additional dichotomization event to produce three
bunches. This suggests that branching may be due to random genetic events instead of a
stable mutation. Furthermore, field performance data were not significantly different for
phenological or yield traits between clones producing one, two, or three bunches. Thus,
selection for increased number of bunches may not be warranted in this Musa population.

Floral induction constitutes an important step in the morphogenesis of flowering plants and signals an irreversible transition from vegetative to reproductive growth. In many annual species, this phenological shift is controlled by hormonal changes that are triggered by external factors such as photoperiod, thermoperiod, and soil fertility (Major, 1980). The nature of the flowering stimulus is not known for bananas (Musa sp. L.), but the anatomical modifications associated with floral induction are rather well described (Israeli and Blumenfeld, 1985; Robinson, 1996; Stover and Simmonds, 1987).

Robinson (1996) described the inflorescence as a single spike with a stout peduncle bearing biseriate nodal clusters of flowers. Each nodal cluster is subtended by a bract that protects the juvenile flowers. The peduncle carries pistillate flowers at its proximal end and staminate flowers at its distal end, while the middle section may contain clusters of hermaphrodite flowers. Only pistillate flowers have well-formed ovaries that may develop into edible fruits.

Variation that may have taxonomic value in Musa has been reported for several inflorescence attributes, such as the presence or absence of hermaphrodite flowers and the persistence of the male flowers (Ortiz, 1997;

Received for publication 16 July 1999. Accepted for publication 21 Dec. 1999. This research was supported in part by a grant from the Directorate General for International Cooperation (DGIC, ex B ADC, Belgium). Manuscript no. IITA/99/JA/33. The cost of publishing this paper was defrayed in part by the payment of page charges. Under postal regulations, this paper therefore must be hereby marked advertisement solely to indicate this fact

${ }^{1}$ International mailing address: IITA, c/o L.W Lambourn \& Co., 26 Dingwall Road, Croydon CR9 3EE,England.E-mail: A.Tenkouano@ satmail.bt.com
Swennen, 1990). Considerable genetic variation occurs in the orientation of the mature inflorescence (Ortiz and Vuylsteke, 1998a) and the number of nodal clusters among bananas (Ortiz and Vuylsteke, 1998b). However, little polymorphism has been reported for the number of inflorescences.

Tissue culture often produces plants that deviate from the phenotype of the explant donor (Vuylsteke, 1998). This is referred to as somaclonal variation, and affects floral and reproductive features in plantains (Vuylsteke, 1998). Robinson (1996) considered that nearly all somaclonal variants of Musa species have inferior phenotypes, although he suggested that horticulturally superior or disease-resistant plants could be obtained. Somaclonal variation can contribute to crop improvement if valuable and genetically stable clones can be selected and regenerated. This depends on the extent to which phenotypic superiority is not determined by physiological factors that are sensitive to environmental fluctuations.

Crop productivity can be enhanced by manipulating yield components (Rasmusson and Cannel, 1970). In cereal species, for example, increased yield has often been associated with an increased number of seeds. Plants that produce several bunches have been occasionally observed in Musa. Stover and Simmonds (1987) reported an unusual plant of 'Grande Naine' with double dichotomy of the pseudostem and an inflorescence on each pseudostem. The occurrence of multiple bunches was also reported by Tang (1995) for Cavendish bananas (Musa sp., AAA group) in Taiwan, and by Odeigah (1997) for plantains (AAB group) in Nigeria. Whether inflorescence dichotomy may lead to increased plant productivity is an attractive hypothesis, but this has not received much attention.

The objectives of this study were to: 1) determine the relative occurrence and persistence of the multiple-bunch phenotype and 2) compare the field growth characteristics of plants with different inflorescence morphotypes.

\section{Materials and Methods}

A single sucker of the cultivar UNN from a plant showing the double-bunch phenotype was obtained from the Univ. of Nigeria (Nsukka, Enugu State) in 1994. Meristematic tissue was excised from the sucker and cultured in vitro for 6 weeks (Vuylsteke et al., 1990). Ninety-five seedlings were obtained and acclimatized for 6 to 8 weeks in a greenhouse, prior to transfer to the field. Forty tissue-cultured plantlets were also obtained from each of two other cultivars, 'Agbagba' (False Horn plantain) and 'Obino l'ewai' (French plantain), that produce only one bunch per plant. These served as controls for the study. The plants were field established in June 1995 at three locations in Nigeria, following a north-south gradient in rainfall and soil fertility characteristics: Abuja (lat. $9^{\circ} 16^{`} \mathrm{~N}$, long. $7^{\circ} 20^{\prime} \mathrm{E} ; 1200 \mathrm{~mm}$ rainfall; ferris luvisol), Ibadan (lat. $7^{\circ} 31^{\prime} \mathrm{N}$, long. $3^{\circ} 54^{\prime} \mathrm{E} ; 1300 \mathrm{~mm}$ rainfall; slightly acidic alfisol), and Onne (lat. $4^{\circ} 51^{\prime} \mathrm{N}$, long. $7^{\circ} 03{ }^{\prime} \mathrm{E} ; 2400 \mathrm{~mm}$ rainfall; highly acidic ultisol). The number of plants established at Onne was 75 for 'UNN', 20 for 'Obino l'ewai', and 20 for 'Agbagba'. At the other two locations, 10 plants of each genotype were established in the field. The field layout was a completely randomized design with single-plant replicates at each location. Plant spacing was $3 \mathrm{~m}$ between rows and $2 \mathrm{~m}$ within rows, and cultural practices and fertilizer application were as described by Swennen (1990).

Several plants did not survive to flowering stage because of drought stress or wind damage. For each remaining plant, data on phenological and yield traits in the plant crop and the first ratoon were recorded. The phenological characteristics included the number of days to flowering, plant height at flowering, number of leaves formed until flowering stage, and number of days elapsed between flowering and harvest (henceforth referred to as fruit filling time). The time to flowering of a stand in the ratoon crop was calculated from the flowering date of the stand in the plant crop. The yield traits were: number of bunches, aggregate bunch weight, number of nodal fruit clusters (hands), number of fruits, average fruit length, and average fruit circumference.

The plants were grouped according to the number of bunches in each crop cycle. Concordance analysis was carried out to determine the proportion of plants that showed the same inflorescence phenotype in both crop cycles, excluding dead plants. The concordance coefficient, denoted CC, was calculated as follows:

$$
\mathrm{CC}=100 \times \frac{\Sigma_{\mathrm{i}} \mathrm{N}_{\mathrm{ii}}}{\Sigma_{\mathrm{i}} \mathrm{N}_{\mathrm{ii}}+\Sigma_{\mathrm{ij}} \mathrm{N}_{\mathrm{ij}}}, \mathrm{i} \neq \mathrm{j}
$$

where $\mathrm{N}_{\mathrm{ii}}$ is the number of plants that expressed the same number of bunches in the 
plant crop and in the ratoon crop, $\mathrm{N}_{\mathrm{ij}}$ is the number of plants that produced different numbers of bunches in the plant crop and in the ratoon crop, and the subscripts $i$ and $j$ refer to the number of classes in the plant crop and the ratoon crop, respectively. A concordance coefficient approaching zero would indicate completely random occurrence of the different inflorescence classes across crop cycles. In contrast, a coefficient near unity would suggest a high probability that a plant expressing a given phenotype in a given crop cycle would express the same phenotype in subsequent crop cycles. We could not perform a contingency analysis to test for independence of distribution of the inflorescence classes in the plant crop compared to the first ratoon crop because of small cell sizes.

The data were subjected to a combined analysis of variance and multiple comparison of means using the PROC GLM command in SAS (SAS Institute, 1992), based on the following three-way factorial model:

$$
\begin{aligned}
\mathrm{Y}_{\mathrm{ijk}}= & \mu+\alpha_{\mathrm{i}}+\beta_{\mathrm{j}}+\gamma_{\mathrm{k}}+(\alpha \beta)_{\mathrm{ij}}+(\alpha \gamma)_{\mathrm{ik}}+(\beta \gamma)_{\mathrm{jk}} \\
& +(\alpha \beta \gamma)_{\mathrm{ijk}}+\varepsilon_{\mathrm{ijk}}
\end{aligned}
$$

where $Y_{i j k}$ is the observed performance of the $\mathrm{i}^{\text {th }}$ genotype at the $\mathrm{j}^{\text {th }}$ location in the $\mathrm{k}^{\text {th }}$ crop cycle, $\mu$ is the overall mean of the trait, $\alpha_{i}$ is the effect of the $i^{\text {th }}$ genotype $(i=1,2, . ., 5), \beta_{j}$ is the effect of the $j^{\text {th }}$ location $(j=1,2,3), \gamma_{k}$ is the effect associated with the $\mathrm{k}^{\text {th }}$ crop cycle $(\mathrm{k}=$ $1,2),(\alpha \beta)_{\mathrm{ij}}$ is the genotype $\times$ location interaction effect, $(\alpha \gamma)_{\text {ik }}$ is the genotype $\times$ crop interaction, $(\beta \gamma)_{\mathrm{jk}}$ is the location $\times$ crop interaction, $(\alpha \beta \gamma)_{\mathrm{ijk}}$ is the genotype $\times$ location $\times$ crop interaction, and $\varepsilon_{\mathrm{ijk}}$ is the residual associated with each observation.

\section{Results and Discussion}

Occurrence and persistence of multiplebunches. 'Agbagba' and 'Obino l'ewai' produced only single bunches. In contrast, differences in the number of bunches were detected among the plants of 'UNN' at two locations, Abuja and Onne. Multiple bunch formation resulted from single or double dichotomization events in the peduncle during floral development (Fig. 1). At Onne, 39 of the 'UNN' plants had a single bunch in the first crop cycle, 12 had double bunches, and three had triple bunches (Table 1). Most of the plants maintained their inflorescence morphotype in the ratoon crop, resulting in a concordance coefficient of $96 \%$ (Table 1). Only two plants that had a double bunch in the first crop reverted to single bunches in the second crop cycle. At Abuja, three 'UNN' plants produced two bunches and the remaining eight had only single bunches in the first crop cycle, but all plants showed single bunches in the ratoon crop (Table 1). Inflorescence dichotomy was not observed at Ibadan. None of the plants observed produced more bunches in the second cycle than in the first.

Tang (1995) also observed variation in the number of inflorescences produced by plants derived from the same clone. In his study, the frequency of plants with multiple bunches was $21 \%$ in the first generation and $61 \%$ in the


Fig 1. Multiple bunch formation in False Horn plantain cv. UNN, resulting from a (top) single or (bottom) double dichotimization of the floral peduncle.

second generation of clones derived from a meristem culture of a single plant of a triplebunch variant of "Giant Cavendish" (Tang, 1995). Thus, the propensity to produce multiple bunches increased from one generation to the next, an indication that phenotype reversal did not occur in this population. This suggests that bunch dichotomy may result from a nonreversible, but relatively frequent, somatic mutation in meristematic tissues during the development of the inflorescence. In contrast, Odeigah (1997) reported consistent expression of double-bunching in a 'False Horn' plantain across three growth cycles. All the plants, like the accession from which they were derived, produced two bunches. This author attributed the expression of the doublebunch phenotype to a stable genetic mutation.

In the present study, the single-bunch phenotype occurred with a relatively high frequency in the first crop cycle with a few plants expressing a triple-bunch phenotype, despite the fact that the plants were regenerated from a 'UNN' individual with a double-bunch phenotype. Reversion to the single-bunch phenotype was also observed in the second crop cycle of plants that had two bunches in the first cycle. Thus, inflorescence dichotomy was not a genetically stable trait in the 'UNN' accession. Whether such instability was physiologi- 
cal in nature cannot be ruled out, since the multiple-bunch phenotype was not expressed at all locations or in all crop cycles. However, the erratic pattern of switching between singlebunch and double-bunch phenotypes appears to be an inherent characteristic of this accession (Baiyeri, 1994). This could be attributed to random and reversible insertional activation events, such as those caused by transposable elements, and would be consistent with the low frequency of individuals with three bunches. Regardless of the genetic or physiological basis of inflorescence dichotomy, its value as a selection criterion would depend on whether clones with multiple bunches grow and yield better than single-bunch plants.

Crop performance. Significant differences between locations were found for most phenological traits, except for the number of days to flowering. For example, mean plant height was $298 \mathrm{~cm}$ at Ibadan, $315 \mathrm{~cm}$ at Abuja, and $335 \mathrm{~cm}$ at Onne. Similarly, mean fruit filling time was $78 \mathrm{~d}$ at Onne, $91 \mathrm{~d}$ at Ibadan, and 103 $\mathrm{d}$ at Abuja. In contrast, location effects were not significant for yield traits, except fruit length (Table 2). Differences between genotypes were not significant for phenological traits, excluding fruit filling time. Conversely, significant genotype effects were observed for yield traits, except bunch weight (Table 2). Differences due to crop cycles were only significant for the number of days to flowering, but crop cycles significantly interacted with genotypes and locations for the number of hands and the fruit length, respectively (Table 2). Similarly, a significant genotype $\times$ location interaction was only observed for the number of hands, while three-way interaction effects were only significant for the number of leaves (Table 2).

Paired $t$ tests (data not shown) were carried out to compare the performance of 'UNN' plants with different inflorescence morphotypes. The number of days to flowering appeared to decrease as the number of bunches increased, but this was not statistically significant. Thus, inflorescence splitting did not significantly modify the vegetative growth of 'UNN' clones prior to flower emergence. In contrast, fruit filling time of 'UNN' plants was significantly greater in the individuals bearing three bunches than in those individuals with one or two bunches (Table 3). As expected, the number of hands increased with the number of bunches (Fig. 2), although significant variations were also observed within each genotype across locations and crop cycles. Similarly, the number of fruits increased with the number of bunches, but this was associated with reduced fruit length and circumference (Table 3 ). These antagonistic relationships between components of yield may explain the lack of significant differences in bunch weight, which ranged from 5.8 to $7.2 \mathrm{~kg}$ at Onne, 7.2 to $8.1 \mathrm{~kg}$ at Ibadan, and 8.5 to $11.3 \mathrm{~kg}$ at Abuja. This suggested that multiple-bunch phenotypes have no agronomic advantage over single-bunch phenotypes.

The fruit filling time of 'UNN' plants with single-bunch phenotype did not differ from that of the control plants derived from

Table 1. Concordance analysis of the number of plants showing one, two, or three bunches in the plant crop (PC) and ratoon crop (RC) for three plantain accessions grown at three locations in Nigeria.

\begin{tabular}{|c|c|c|c|c|c|c|c|c|c|c|}
\hline \multirow{2}{*}{\multicolumn{2}{|c|}{ No. bunches }} & \multicolumn{9}{|c|}{ Accessions } \\
\hline & & \multicolumn{3}{|c|}{ UNN } & \multicolumn{3}{|c|}{ Obino l'ewai } & \multicolumn{3}{|c|}{ Agbagba } \\
\hline PC & $\mathrm{RC}$ & Onne & Ibadan & Abuja & Onne & Ibadan & Abuja & Onne & Ibadan & Abuja \\
\hline \multicolumn{11}{|c|}{ No. of plants } \\
\hline \multirow[t]{4}{*}{1} & 1 & 33 & 6 & 6 & 10 & 4 & 2 & 12 & 4 & 3 \\
\hline & 2 & 0 & 0 & 0 & 0 & 0 & 0 & 0 & 0 & 0 \\
\hline & 3 & 0 & 0 & 0 & 0 & 0 & 0 & 0 & 0 & 0 \\
\hline & Dead & 6 & 1 & 2 & 2 & 4 & 6 & 1 & 4 & 6 \\
\hline \multirow[t]{4}{*}{2} & 1 & 2 & 0 & 1 & 0 & 0 & 0 & 0 & 0 & 0 \\
\hline & 2 & 10 & 0 & 0 & 0 & 0 & 0 & 0 & 0 & 0 \\
\hline & 3 & 0 & 0 & 0 & 0 & 0 & 0 & 0 & 0 & 0 \\
\hline & Dead & 0 & 0 & 1 & 0 & 0 & 0 & 0 & 0 & 0 \\
\hline \multirow[t]{4}{*}{3} & 1 & 0 & 0 & 0 & 0 & 0 & 0 & 0 & 0 & 0 \\
\hline & 2 & 0 & 0 & 0 & 0 & 0 & 0 & 0 & 0 & 0 \\
\hline & 3 & 2 & 0 & 0 & 0 & 0 & 0 & 0 & 0 & 0 \\
\hline & Dead & 1 & 0 & 0 & 0 & 0 & 0 & 0 & 0 & 0 \\
\hline \multirow{3}{*}{\multicolumn{2}{|c|}{$\begin{array}{l}\text { Total in PC } \\
\text { Total in RC } \\
\mathrm{CC}(\%)^{\mathrm{z}}\end{array}$}} & 54 & 7 & 10 & 12 & 8 & 8 & 13 & 8 & 9 \\
\hline & & 47 & 6 & 7 & 10 & 4 & 2 & 12 & 4 & 3 \\
\hline & & 96 & 100 & 86 & 100 & 100 & 100 & 100 & 100 & 100 \\
\hline
\end{tabular}

${ }^{2}$ Concordance coefficient.

Table 2. Significance tests from combined analysis of variance for some phenological and yield traits of plantain genotypes grown for two crop cycles at three locations in Nigeria.

\begin{tabular}{lcccccccccc}
\hline \hline & & \multicolumn{10}{c}{ Plant traits $^{2}$} \\
\cline { 2 - 11 } Source of variation & df & DTF & DFF & PHT & TNL & BWT & HND & FNB & FTL & FCR \\
\hline Locations (L) & 2 & NS & $* *$ & $*$ & $* * *$ & NS & NS & NS & $* *$ & NS \\
Genotypes (G) & 4 & NS & $* *$ & NS & NS & NS & $* *$ & $*$ & $* *$ & $*$ \\
Crop cycles (C) & 1 & $*$ & NS & NS & NS & NS & NS & NS & NS & NS \\
L $\times$ G & 8 & NS & NS & NS & NS & NS & $*$ & NS & NS & NS \\
L $\times$ C & 2 & NS & NS & NS & NS & NS & NS & NS & $*$ & NS \\
G $\times$ C & 4 & NS & NS & NS & NS & NS & $*$ & NS & NS & NS \\
L $\times$ G $\times$ C & 8 & NS & NS & NS & $*$ & NS & NS & NS & NS & NS \\
CV $(\%)$ & & 12.0 & 21.2 & 13.8 & 19.5 & 19.1 & 17.9 & 19.5 & 18.9 & 14.0 \\
\hline
\end{tabular}

${ }^{2} \mathrm{DTF}=$ number of days to flowering; $\mathrm{DFF}=$ fruit filling time $($ days $) ; \mathrm{PHT}=$ plant height $(\mathrm{cm}), \mathrm{TNL}=$ total number of leaves per plant; BWT $=$ bunch weight $(\mathrm{kg}$ per plant); $\mathrm{HND}=$ number of hands per plant; $\mathrm{FNB}$ $=$ number of fruits per plant; FTL = mean fruit length $(\mathrm{cm})$, and FCR = mean fruit circumference $(\mathrm{cm})$. ${ }^{y}$ One of the three accessions produced plants with one, two, or three bunches. They were considered as different genotypes.

ns, *,**,**** Nonsignificant or significant at $P \leq 0.05,0.01$, or 0.001 , respectively.

Table 3. Phenological and yield characteristics of some plantain genotypes grown in Nigeria. Data are means of two crop cycles and three locations.

\begin{tabular}{lcccc}
\hline \hline & \multicolumn{4}{c}{ Plant traits $^{\mathrm{z}}$} \\
\cline { 2 - 5 } Genotype $^{\mathrm{y}}$ & $\begin{array}{c}\text { Fruit filling } \\
\text { time (days) }\end{array}$ & $\begin{array}{c}\text { No. of } \\
\text { fruits }\end{array}$ & $\begin{array}{c}\text { Fruit } \\
\text { length }(\mathrm{cm})\end{array}$ & $\begin{array}{c}\text { Fruit } \\
\text { circumference (cm) }\end{array}$ \\
\hline UNN (1) & $83.6 \mathrm{c}$ & $39 \mathrm{c}$ & $23.0 \mathrm{a}$ & $14.2 \mathrm{a}$ \\
UNN (2) & $89.4 \mathrm{bc}$ & $55 \mathrm{~b}$ & $17.5 \mathrm{~b}$ & $12.5 \mathrm{~b}$ \\
UNN (3) & $116.6 \mathrm{a}$ & $62 \mathrm{a}$ & $18.9 \mathrm{a}$ & $12.2 \mathrm{~b}$ \\
Agbagba (1) & $91.3 \mathrm{~b}$ & $41 \mathrm{c}$ & $20.8 \mathrm{a}$ & $13.7 \mathrm{a}$ \\
Obino l'ewai (1) & $97.8 \mathrm{~b}$ & $68 \mathrm{a}$ & $15.8 \mathrm{c}$ & $11.6 \mathrm{~b}$ \\
\hline
\end{tabular}

${ }^{2}$ Mean separation within columns by LSD, $P \leq 0.05$

'The figures in parentheses indicate the number of bunches per plant..

'Agbagba' or 'Obino l'ewai', which only produce single bunches (Table 3). Similarly, the yield traits of the 'UNN' clones with singlebunch phenotype did not differ from those of the 'Agbagba' or 'Obino l'ewai' plants (Table $3)$. This contrasted with the results of Odeigah (1997), who reported a nearly $70 \%$ yield advantage in a double-bunch mutant compared with a "typical Local False Horn" control that produced only a single bunch.

The occurrence of bunch dichotomy in the False Horn plantain germplasm pool has been reported in other West African countries. In Ghana, for example, some plantain accessions have derived their native names from their propensity to produce two (e.g., 'Abomienu') or three (e.g., 'Abomiensa') bunches (Hemeng et al., 1995; Schill et al., 1997). However, none of these are widely cultivated by farmers, perhaps because they did not represent any significant yield advantage while requiring more labor, e.g., for propping or postharvest processing. In this study, fruit filling time also increased with the number of bunches. Hence, an extra month would be required to harvest plants with three bunches compared with those with a single bunch, which is certainly not attractive.

Antagonistic relationships have often been observed between components of yield in cereal crops (Rasmusson and Cannel, 1970). This has spurred much discussion about the 


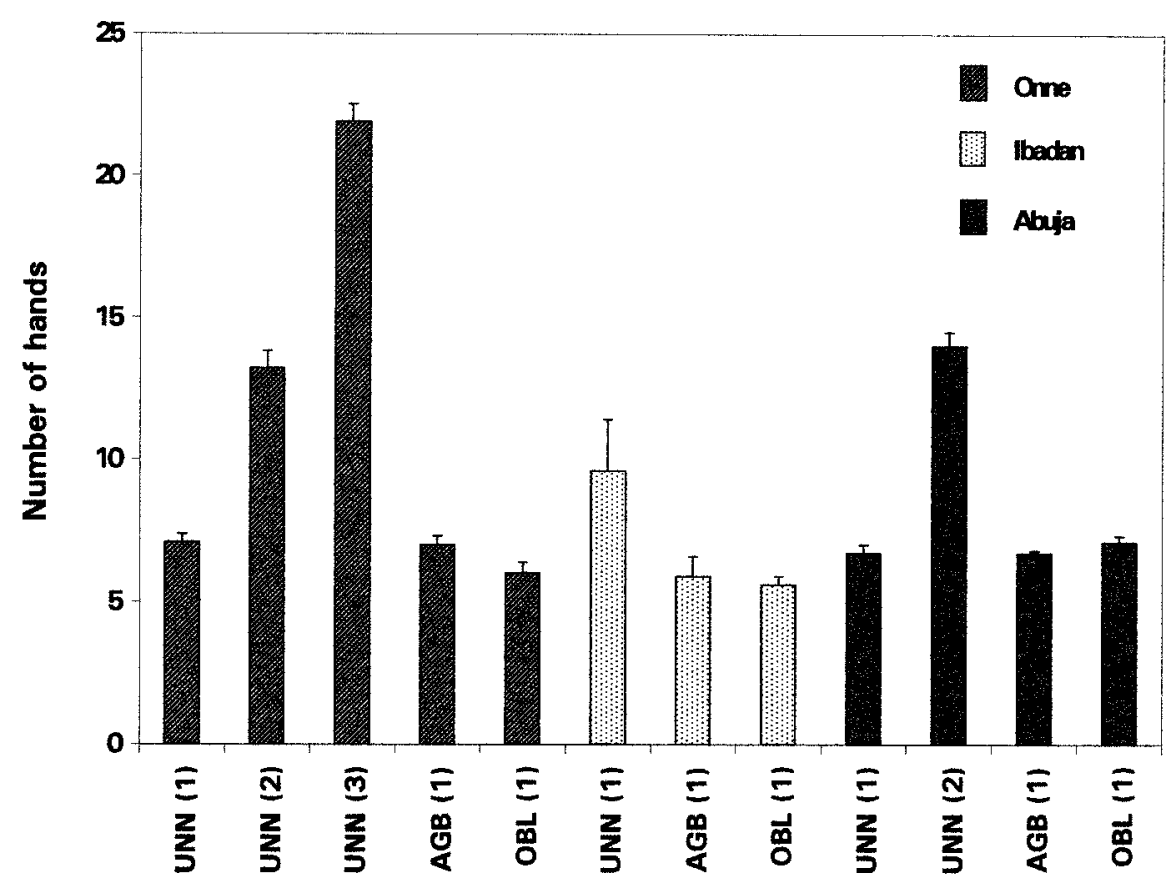

Fig. 2. Number of hands in plantain accessions bearing one, two, or three bunches at three locations in Nigeria. Accessions are 'UNN', 'Agbagba' (AGB), and 'Obino l'ewai' (OBL) and their number of bunches is given in parentheses.

relative value of such components in determining yield. For example, Marshall (1991) suggested that multiculm growth habit was superior to uniculm habit in wheat, whereas Whan et al. (1988) found no evidence that single culm habit was detrimental to yield. The results of the present study also suggest that selection for increased number of bunches in order to increase yield may not be warranted in Musa.

\section{Literature Cited}

Baiyeri, K.P. 1994. Preserving prodigious plantains. Spore 49:13.
Hemeng, O.B., K.A. Oduro, I. Ofori, and B. Banful (eds.). 1995. Plantain production in Ghana. Final report of field survey submitted to National Agriculture Research project (NARP) Secretariat, Accra, Ghana.

Israeli, Y. and A. Blumenfeld. 1985. Musa, p. 390409. In: A.H. Halevy (ed.). Handbook of flowering, Vol. 3. CRC Press, Boca Raton, Fla. ing, p. 1-15. In: W.R. Fehr and H.H. Hadley (eds.). Hybridization of crop plants. Amer. Soc. Agron., Madison, Wis.

Marshall, D.R. 1991. Alternative approaches and perspectives in breeding for higher yields. Field Crops Res. 26:171-190.

Odeigah, P.G.C. 1997. "Double bunching" in a plantain germplasm in Nigeria: A new geno-
Major, D.J. 1980. Environmental effects on flower- type. Genet. Res. and Crop Evol. 44:1-3.

Ortiz, R. 1997. Morphological variation in Musa germplasm. Genet. Res. and Crop Evol. 44:393404

Ortiz R. and D. Vuylsteke. 1998a. Segregation of bunch orientation in plantain and banana hybrids. Euphytica 101:79-82.

Ortiz R. and D. Vuylsteke. 1998b. Quantitative variation and phenotypic correlations in banana and plantain. Scientia Hort. 72:239-253.

Rasmusson, D.C. and R.Q. Cannel. 1970. Selection for grain yield and components of yield in barley. Crop Sci. 10:51-54.

Robinson, J.C. 1996. Bananas and plantains. CAB Intl., Wallingford, U.K.

SAS Institute. 1992. SAS user's guide, release 6.03 ed. Stat. Analysis Systems Inst., Cary, N.C.

Schill, P., K. Afreh-Nuamah, C. Gold, F. UlzenApiah, E. Paa Kwesi, S.A. Peprah, and J. K. Twumasi. 1997. Farmers' perception of constraints in plantain production in Ghana. Plant Health Mgt. Res. Monogr. No. 5. Intl. Inst. Trop. Agr., Ibadan, Nigeria.

Stover, R.H. and N.W. Simmonds. 1987. Bananas. 3rd ed. Longman, London.

Swennen, R. 1990. Plantain cultivation under West African conditions: A reference manual. Intl. Inst. Trop. Agr., Ibadan, Nigeria.

Tang, C.Y. 1995. Variability of bunch type in clones of a banana with several bunches. InfoMusa $4: 17-18$.

Vuylsteke, D.R. 1998. Field performance of banana micropropagules and somaclones, p. 219-231. In: S.M. Jain, D.S. Brar, and B.S. Ahloowalia (eds.). Somaclonal variation and induced mutation in crop improvement. Kluwer Acad. Publ., Dordrecht, The Netherlands.

Vuylsteke D., R. Swennen, and E. De Langhe. 1990. Tissue culture technology for the improvement of African plantains, p. 316-337. In: R.A. Fullerton and R.H. Stover (eds.). Sigatoka leaf spot diseases of bananas. Proc. Intl. Wkshp., San Jose, Costa Rica, 28 Mar.-1 Apr. 1989. Intl. Network for the Improvement of Banana and Plantain, Montpellier, France.

Whan, B.R., R. Delane, and R. Gilmour. 1988. The potential of reduced tillering wheats in dry environments, p. 907-911 In:T.E. Miller and R.M.D Koebner (eds.). Proc. 7th Intl. Wheat Genet. Symp., Inst. Plant Sci. Res. Cambridge Lab., Trumpington, England. 